\title{
Tribological behavior of three fatty acid ionic liquids in the lubrication of different material pairs
}

\author{
N. Rivera ${ }^{\mathrm{a}}$, A. García ${ }^{\mathrm{b}}$, A. Fernández-González ${ }^{\mathrm{c}}$, D. Blanco ${ }^{\mathrm{b}}$, R. González ${ }^{\mathrm{a}, \mathrm{d}}$, A. Hernández Battez ${ }^{\mathrm{b}, \mathrm{d}}$ \\ ${ }^{a}$ Department of Marine Science and Technology, University of Oviedo, Asturias, Spain \\ ${ }^{\mathrm{b}}$ Department of Construction and Manufacturing Engineering, University of Oviedo, Asturias, Spain \\ ${ }^{\mathrm{c}}$ Department of Physical and Analytical Chemistry, University of Oviedo, Asturias, Spain \\ ${ }^{\mathrm{d}}$ Department of Design and Engineering, Bournemouth University, Poole, BH12 5BB, UK \\ (*) Email: garciamaralberto@ uniovi.es
}

\begin{abstract}
Tribological behavior of three Fatty Acid anion-based Ionic Liquids (FAILs) with the same ammonium cation $\left(\left[\mathrm{N}_{8881}\right]\right)$ and different anions $\left(\left[\mathrm{C}_{16: 0}\right],\left[\mathrm{C}_{12: 0}\right]\right.$ and $\left.\left[\mathrm{C}_{8: 0}\right]\right)$ were studied. Four different tribopairs (steelsteel, aluminum-steel, bronze-steel and tungsten carbide-steel) were tested for each FAIL using a ball-ondisc reciprocating test for $30 \mathrm{~min}$ (room temperature, $50 \mathrm{~N}$-load, $4 \mathrm{~mm}$ of stroke length, and $15 \mathrm{~Hz}-$ frequency). Aluminum and tungsten carbide surfaces did not show evidence of oxidation changes, contact pressure and hardness being, respectively, the main parameters controlling tribological behavior. Bronze and steel samples showed surface oxidation changes during tests, which influenced friction and/or wear results. An increase in alkyl chain length of the anion led to an increase in tin oxidation of bronze and the formation of a low friction film of $\mathrm{Fe}_{3} \mathrm{O}_{4}$ on steel.
\end{abstract}

Keywords: ionic liquids; fatty acids; friction; wear

\section{Introduction}

Industry is increasingly demanding lubricants with better benefits in both in friction and wear reduction.

Zinc dialkyldithiophosphate (ZDDP) is traditionally considered as the most effective antioxidant and antiwear additive for lubricants [1]. However, recently established environmental regulations have recommended a reduction in the use of ZDDP as an oil additive due to the ash generation that occurs when it is exposed to high temperatures (very harmful to the exhaust catalyst in combustion engines), and its toxicity to the aquatic environment [2].

Ionic liquids (ILs) have been shown to be good candidates for use in lubrication, both as neat lubricant or as an additive. Several authors have studied different ILs as lubricants in the last 18 years [3-6]. Thermochemical stability, low melting point or their inherent polarity are some of the properties of ILs that lead to their good performance in lubrication [7, 8]. IL lubrication research is usually focused on steel-steel contacts, because steel is probably the most common material in industry [9-16]. Lightweight materials (aluminum alloys and silicon) are also widely used [17-23]. In addition, other materials and coatings used in engineering applications, such as titanium, copper, sialon ceramics, electro-deposited $\mathrm{Ni} / \mathrm{Si}_{3} \mathrm{~N}_{4}$ composed coating, have also been tested when lubricated with ILs in recent years [24-30].

Some ammonium cation-based ionic liquids were studied in order to prove their feasibility for use in lubrication, obtaining both great antifriction and antiwear results [31-32] and good physicochemical and 
environmental properties [33-36]. Despite the fact that this family of ILs has usually been employed as lubricant additives [37, 38], research has been conducted using this kind of IL as neat lubricant [15, 32]. Protic ammonium carboxylate ionic liquids showed both wear and friction reduction behavior on copper surfaces, due to the formation of a tribofilm, compared with a polyalphaolefin (PAO) [9]. Espinosa et al. compared the tribological behavior of carboxylate anion ionic liquids with that of organophosphate and sulfonate ionic liquids [25]. Because of its long alkyl chain, the carboxylate anion showed high solubility in PAO base oil and the formation of a thin antiwear tribofilm. On the other hand, tetraalkylammonium fatty acid ionic liquids showed significantly lower friction compared with polyol ester-based oils [40]. In recent years, one of the goals of industry has been to obtain lubricants with low toxicity and/or high biodegradability, and vegetable oils are good candidates to replace petroleum-based oils [41]. The new generation of green oils also requires new additives in order to maintain their good ecological properties [42]. Fatty Acid Ionic Liquids (FAILs) are compounds that potentially combine the physicochemical characteristics of ionic liquids with the high biodegradability and low toxicity of vegetable oils. So, they can be used as neat lubricant [43] or as an additive to vegetable oil lubricants [44].

Using fatty acids in the synthesis of ILs was reported for the first time in 2013 [45]. After this point, few works regarding the feasibility ofemploying these family of ionic liquids as lubricants or lubricants additive have been published [46-52]. This paper studies three novel ionic liquids synthesized from fatty acids, using the same ammonium cation $\left(\left[\mathrm{N}_{8881}\right]\right)$ and three different anions with different carbon chain length ([ $\left.\mathrm{C}_{16: 0}\right],\left[\mathrm{C}_{12: 0}\right]$ and $\left.\left[\mathrm{C}_{8: 0}\right]\right)$, with the aim of evaluating for the first time the tribological behavior of these substances in four different material pairs (steel-steel, steel-aluminum alloy, steel-bronze and steeltungsten carbide), developing halogen-, phosphorus-, and sulfur-free ionic liquids that can be employed in lubrication.

\section{Experimental details}

\subsection{Ionic liquids derived from fatty acids (FAILs)}

The ionic liquids methyltrioctylammonium palmitate $\left(\left[\mathrm{N}_{8881}\right]\left[\mathrm{C}_{16: 0}\right]\right)$, methyltrioctylammonium laurate $\left(\left[\mathrm{N}_{8881}\right]\left[\mathrm{C}_{12: 0}\right]\right)$ and methyltrioctylammonium octanoate $\left(\left[\mathrm{N}_{8881}\right]\left[\mathrm{C}_{8: 0}\right]\right)$ were synthesized from palmitic, lauric and octanoic fatty acids, respectively, using a salt metathesis reaction. This process can be summarized in three steps: ester formation, metathesis reaction and finally, solvent elimination. The experimental details of the synthesis process have been detailed in a previous study [53]. A differential scanning calorimetry (DSC) Mettler Toledo 822 were used to obtain the melting temperature $\left(\mathrm{T}_{\mathrm{m}}\right)$ with a 
scan rate of $5{ }^{\circ} \mathrm{C} \min ^{-1}$ from $-50{ }^{\circ} \mathrm{C}$ to $50{ }^{\circ} \mathrm{C}$, a resolution lower than $0.04 \mu \mathrm{W}$ and a temperature precision of $\pm 0.2{ }^{\circ} \mathrm{C}$. In addition, a Metrohm 899 coulometer Karl Fischer titration was employed to determine the water content $\left(\mathrm{w}_{\mathrm{H} 20}\right)$ of the ionic liquids. Figure 1 shows the chemical structure of the ILs. The density of these ILs ranges from 0.878 to $0.899 \mathrm{~g} \cdot \mathrm{cm}^{-3}$ at $20{ }^{\circ} \mathrm{C}$, and their viscosity values are taken from [4552]. Table 1 resumes these mentioned properties.

Table 1 Physicochemical properties of the ionic liquids.

\begin{tabular}{|c|c|c|c|c|c|c|}
\hline \multirow[b]{2}{*}{ Ionic liquids } & \multicolumn{3}{|c|}{ Kinematic viscosity $\left(\mathrm{mm}^{2} \cdot \mathrm{s}^{-1}\right)$} & \multirow{2}{*}{$\begin{array}{c}\text { Viscosity } \\
\text { index } \\
\text { ASTM D2270 }\end{array}$} & \multirow{2}{*}{$\begin{array}{c}\mathrm{T}_{\mathrm{m}} \\
\left({ }^{\circ} \mathrm{C}\right)\end{array}$} & \multirow{2}{*}{$\begin{array}{c}\mathrm{W}_{\mathrm{H} 20} \\
(\mathrm{ppm})\end{array}$} \\
\hline & $20^{\circ} \mathrm{C}$ & $40^{\circ} \mathrm{C}$ & $100^{\circ} \mathrm{C}$ & & & \\
\hline$\left[\mathrm{N}_{8881}\right]\left[\mathrm{C}_{16: 0}\right]$ & 2597.3 & 596.27 & 37.35 & 99 & -2 & 29600 \\
\hline$\left[\mathrm{N}_{8881}\right]\left[\mathrm{C}_{12: 0}\right]$ & 3319.7 & 715.69 & 36.93 & 85 & -10 & 12200 \\
\hline$\left[\mathrm{N}_{8881}\right]\left[\mathrm{C}_{8: 0}\right]$ & 5704.9 & 1121.20 & 48.55 & 85 & 19 & 30500 \\
\hline
\end{tabular}
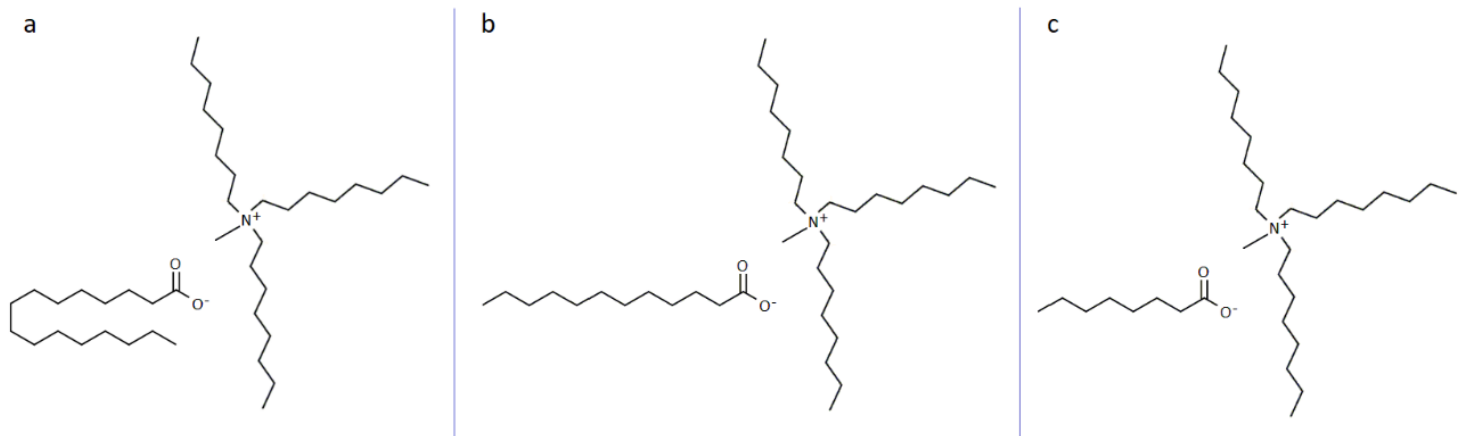

Fig. 1 Chemical structure of the ILs: a) $\left[\mathrm{N}_{8881}\right]\left[\mathrm{C}_{16: 0}\right]$, b) $\left[\mathrm{N}_{8881}\right]\left[\mathrm{C}_{12: 0}\right]$ and c) $\left[\mathrm{N}_{8881}\right]\left[\mathrm{C}_{8: 0}\right]$.

\subsection{Tribological tests}

All the ionic liquids were tribologically tested in a reciprocating ball-on-disc configuration using a Bruker UMT-3 tribometer. The balls used as the upper specimen are manufactured from AISI 52100 steel with 6 mm-diameter, hardness of 58-66 HRC, and less than $0.05 \mu \mathrm{m} \mathrm{R}$ of surface finish. The description of discs (lower specimen) material is presented in Table 2. 
Table 2 Materials of the discs used in the tribological tests.

\begin{tabular}{lcccc}
\hline Materials & $\begin{array}{c}\text { Roughness*, } \\
\mathrm{R}_{\mathrm{a}}(\mu \mathrm{m})\end{array}$ & Hardness* & $\begin{array}{c}\text { Young } \\
\text { modulus** } \\
(\mathrm{GPa})\end{array}$ & $\begin{array}{c}\text { Poisson's } \\
\text { ratio*** }\end{array}$ \\
\hline Steel AISI 52100 & 0.018 & $225 \mathrm{HV}_{0.1}$ & 210 & 0.30 \\
Aluminum 6082 T6 & 0.025 & $116 \mathrm{HV}_{0.1}$ & 69 & 0.34 \\
Bronze PB1 BS 1400 & 0.027 & $219 \mathrm{HV}_{0.1}$ & 100 & 0.34 \\
Tungsten Carbide WC6Co & 0.022 & $1843 \mathrm{HV}_{0.3}$ & 670 & 0.27 \\
\hline
\end{tabular}

* Measured by authors. ** Provided by suppliers.

The friction and wear reciprocating tests were made at $50 \mathrm{~N}$-load (corresponding to a maximum contact pressure of 2.43 GPa for the steel-steel pair, 1.54 GPa for the steel-aluminum pair, $1.84 \mathrm{GPa}$ for the steelbronze pair, and 3.2 GPa for the steel-WC pair). The frequency was adjusted to $15 \mathrm{~Hz}$ and the stroke length to $4 \mathrm{~mm}$. All tests had a duration of $30 \mathrm{~min}$ and were conducted at room temperature $\left(25^{\circ} \mathrm{C}\right)$. The volume of ionic liquid used was $25 \mu \mathrm{L}$, which was put on the disc's surface before beginning the test. Each test condition was repeated at least two times.

Both specimens (ball and disc) were cleaned in petroleum ether for $5 \mathrm{~min}$ in an ultrasonic bath, rinsed in ethanol and then dried with hot air before tribological tests. The specimens were cleaned again in petroleum ether for $5 \mathrm{~min}$ in an ultrasonic bath and dried with hot air after tribological tests. Then, the worn volume on the disc surface was measured using a confocal microscope.

\subsection{Surface Analysis}

After tribological testing, the wear scar surface was analyzed using SEM-EDS and XPS techniques. XPS experiments were performed using monochromatic Al radiation (1486.74 eV) focused on the wear scar. Step energy of high resolution spectra was $0.1 \mathrm{eV}$ with a pass energy of $60 \mathrm{eV}$ and dwell time of $0.2 \mathrm{~s}$. Spectra were corrected assuming spurious carbon at $284.6 \mathrm{eV}$. Curve fitting was performed using $30 \%$ Gaussian-70\% Lorentzian product for every case, except iron, where this product was modified using an exponential blend with $\mathrm{k}=1.5$ for $\mathrm{Fe}(\mathrm{III})$ peaks and $\mathrm{k}=0.65$ for $\mathrm{Fe}^{0}$.

\section{Results and discussion}

\subsection{Friction and wear}

Figure 2 shows the evolution of the friction coefficient during tribological tests. The result of the most representative test of each material-ionic liquid combination is reported. The friction coefficient was stable in general, particularly from the middle of the testing period onwards. Lubrication with the $\left[\mathrm{N}_{8881}\right]\left[\mathrm{C}_{16: 0}\right]$ 
ionic liquid showed the lowest coefficient of friction on all surfaces, except bronze, where the coefficient of friction with this substance was the highest. The $\left[\mathrm{N}_{8881}\right]\left[\mathrm{C}_{12: 0}\right]$ ionic liquid showed better antifriction properties than its $\left[\mathrm{N}_{8881}\right]\left[\mathrm{C}_{8: 0}\right]$ counterpart on all surfaces.
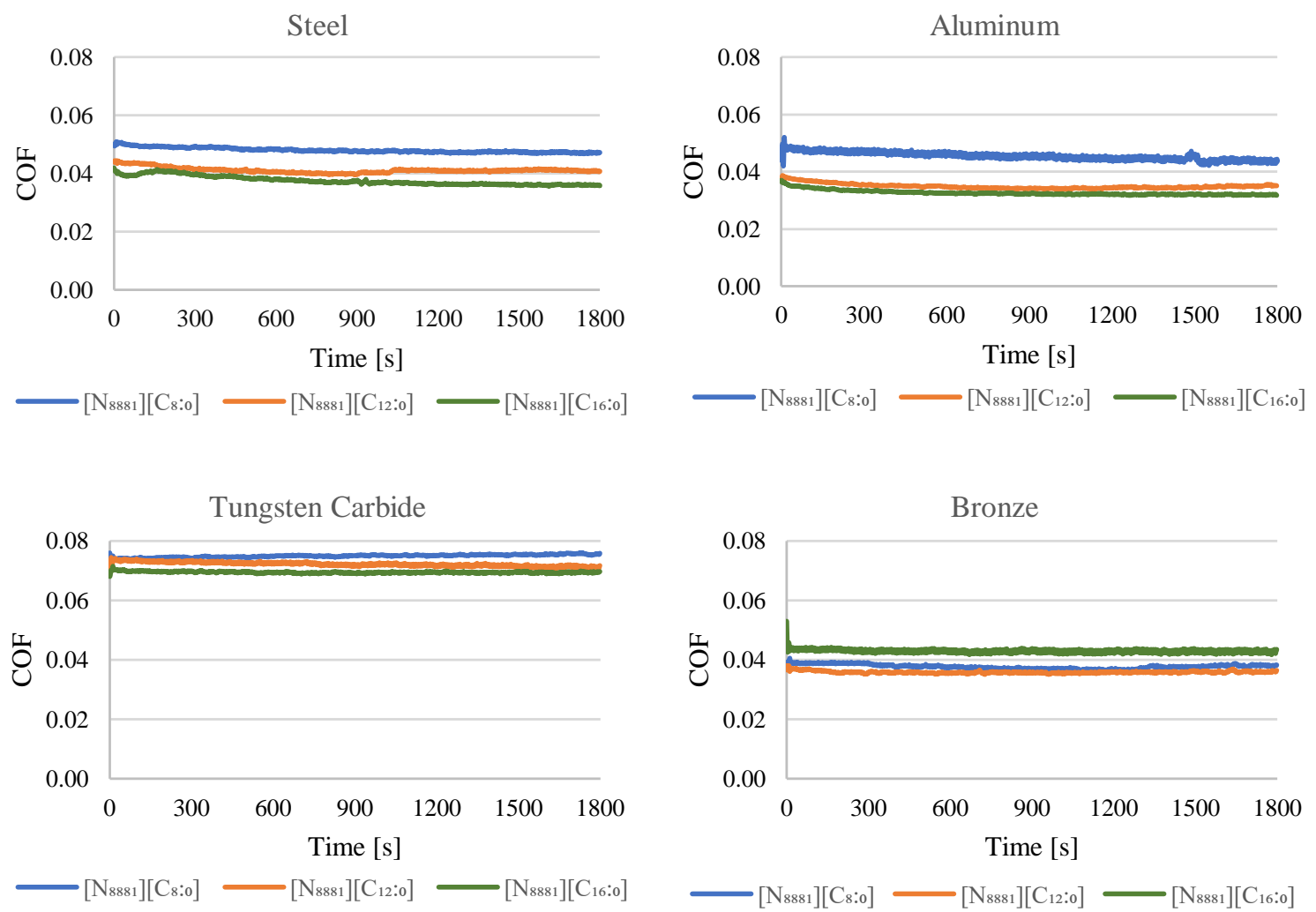

Fig. 2 Evolution of coefficient of friction during tribological tests.

Figure 3 compares the mean values of coefficient of friction obtained in the tribological tests. Differences between the average coefficient of friction obtained with the four tested materials can be explained by considering parameters such as the viscosity of the ionic liquids, contact pressure and hardness of the specimens. An increase in Young's modulus values leads to higher Hertz pressures and this results in lower lubricant film thicknesses. The higher pressure in the tests carried out with WC discs resulted in the highest coefficient of friction, whereas the tests with the steel-steel pair had intermediate results, in agreement with the intermediate Hertz pressure and the roughness of the steel disc being the lowest of the four materials. On the other hand, the aluminum-steel and the bronze-steel pairs showed similar, low friction coefficient values due to their similar Hertz pressure values and the similar surface roughness of the aluminum and bronze discs. 
Although no significant differences in friction were found between ILs in the lubrication of each material pair, the average values recorded showed that an increase in the alkyl chain length leads to a slight decrease in the COF. Gusain et al. [54] reported the relationship between the cation chain length of ammoniumbased ionic liquids and the COF, showing that a longer alkyl chain leads to both lower friction and wear, due to the strong adsorption onto the surface, forming a tribofilm of low shear strength. However, the tribological tests with the $\left[\mathrm{N}_{8881}\right]\left[\mathrm{C}_{16: 0}\right]$ ionic liquid and the bronze discs showed a slightly higher COF than the rest of the ionic liquids on this material.

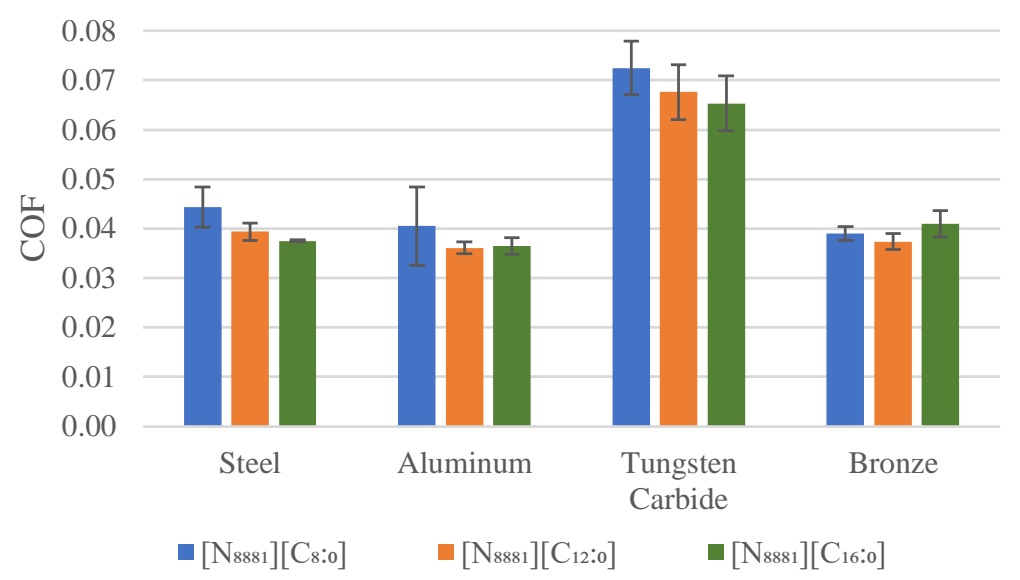

Fig. 3 Average, minimum and maximum values of coefficient of friction.

The friction coefficient and wear values measured during and after tribological tests, respectively, demonstrated that tribological tests were performed under a mixed lubrication regime. Despite the viscosity differences between the ionic liquid samples, the antifriction and antiwear behavior is probably more closely related to chemical interaction between the ionic liquid and the surface. Aluminum samples showed greater wear volume than the other three materials due to their lower hardness. It can be observed that the wear volume decreased with the increase in carbon chain length in the anion, probably related to the low shear strength films reported by Gusain [54]. On the steel and bronze discs, the lowest average wear volume was detected in samples lubricated with hexadecanoate (palmitate) anion-based IL, while the greatest wear volume values were recorded for the dodecanate (laurate) anion-based IL. In tungsten carbide samples, differences in wear volume were not detected between the ionic liquids, probably because the high hardness is the main parameter controlling the wear process rather than the viscosity of the ionic liquid and possible tribofilm formation. The lower wear volume of the WC surface in comparison with aluminum, bronze and steel surfaces is also due to the higher hardness of the former. 


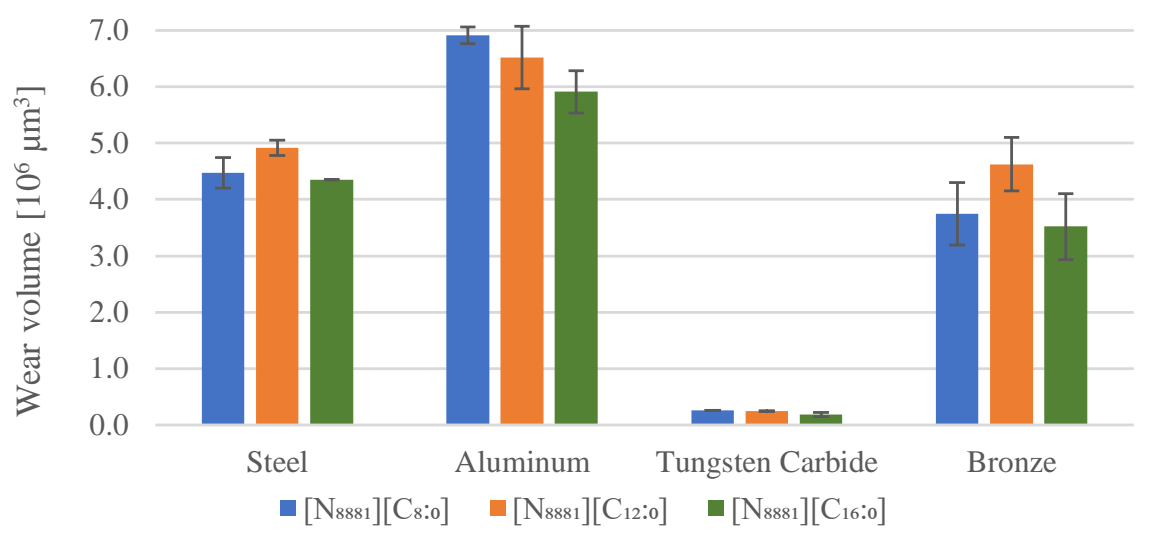

Fig. 4 Wear volume on the disc's surface.

\subsection{Surface analysis}

Figs. 5-8 show the SEM images of the discs after tribological tests. The morphology of the wear scar on the steel discs (Fig. 5) was the same for all the ionic liquids used. Similar behavior was found on the aluminum discs (Fig. 6). The images on the WC discs show the smallest wear scars and at increasing alkyl chain length of the anion the wear scar is almost undetectable (Fig. 7). These results are in line with the hardness of WC, which is considerably higher than that of the ball, which consequently barely generates wear on the disc. On the other hand, the bronze samples (Fig. 8) lubricated with the $\left[\mathrm{N}_{8881}\right]\left[\mathrm{C}_{12: 0}\right]$ IL showed the greatest damage in the SEM analysis.
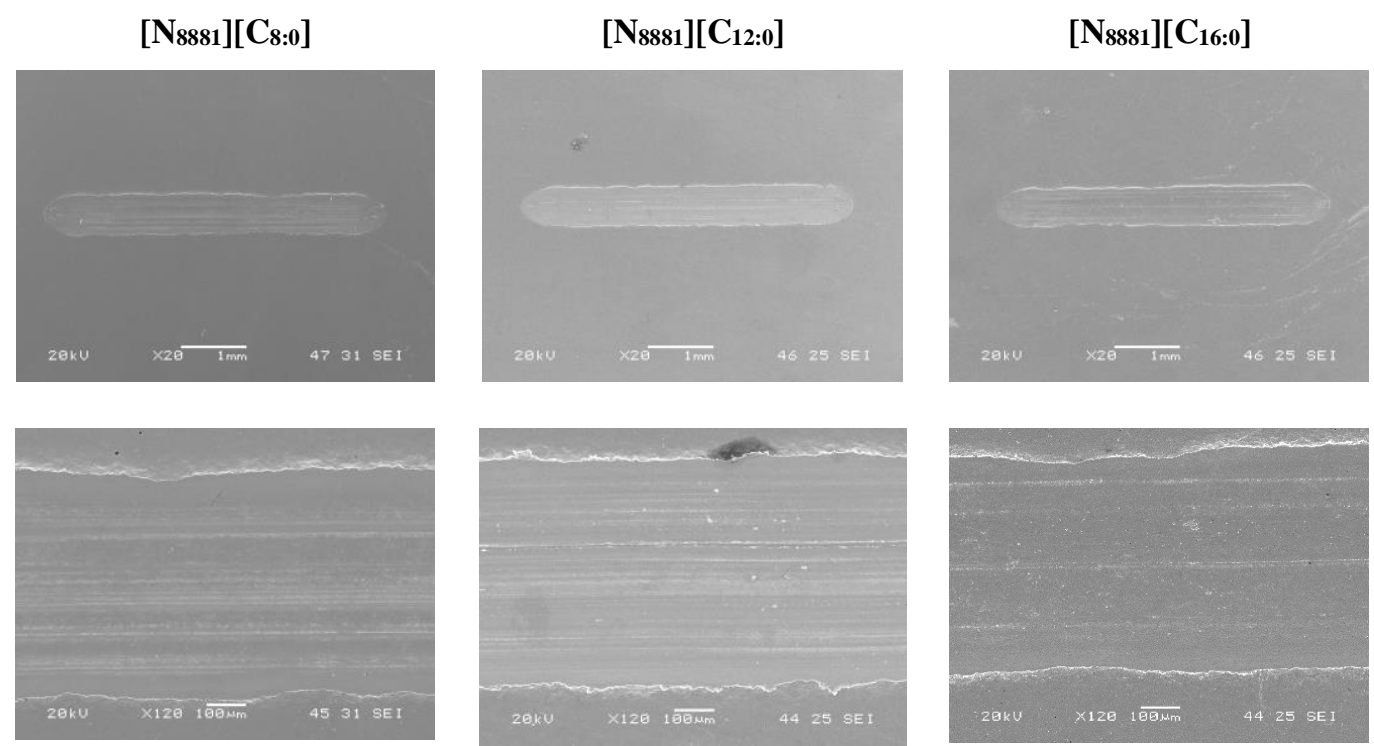

Fig. 5 Wear scar on the steel discs after tribological tests with ionic liquid lubrication. 

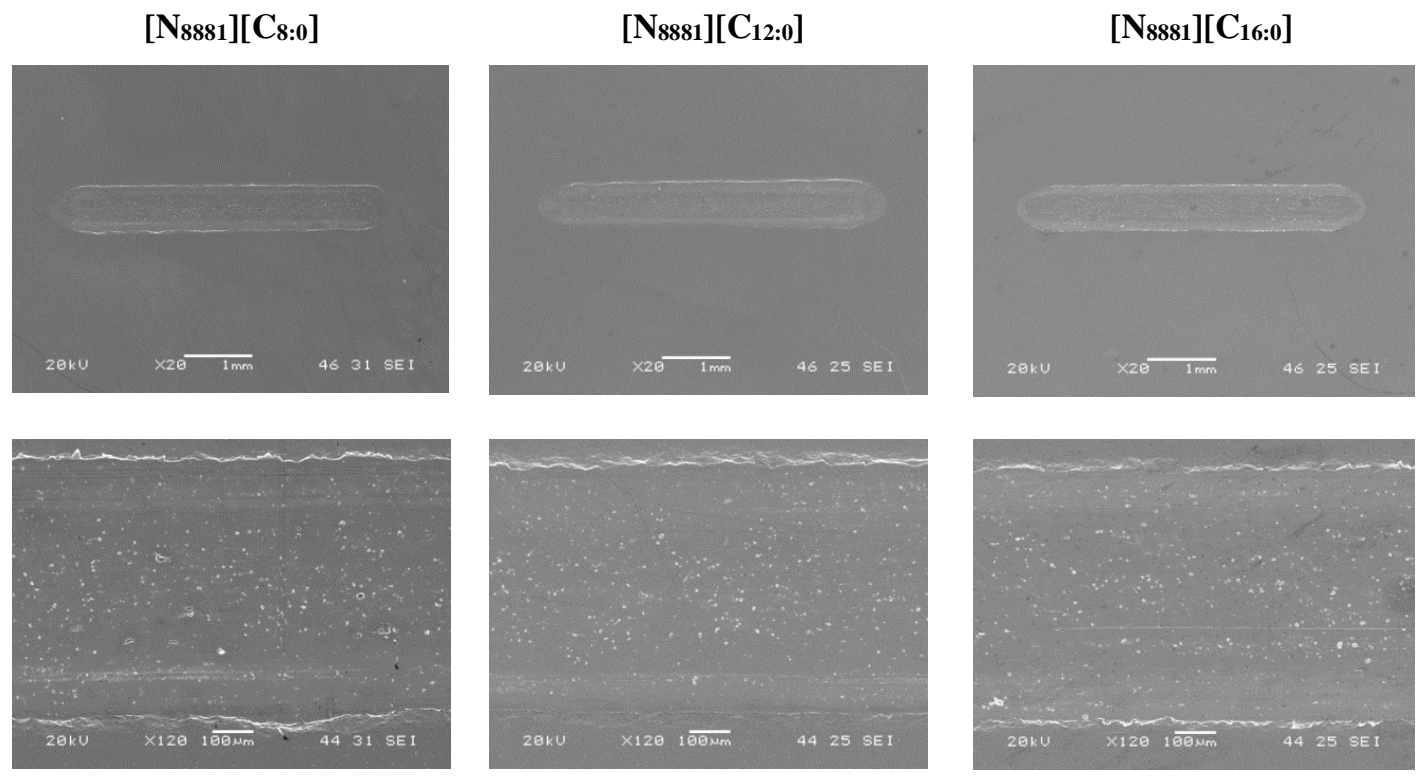

Fig. 6 Wear scar on the aluminum discs after tribological tests with ionic liquid lubrication.
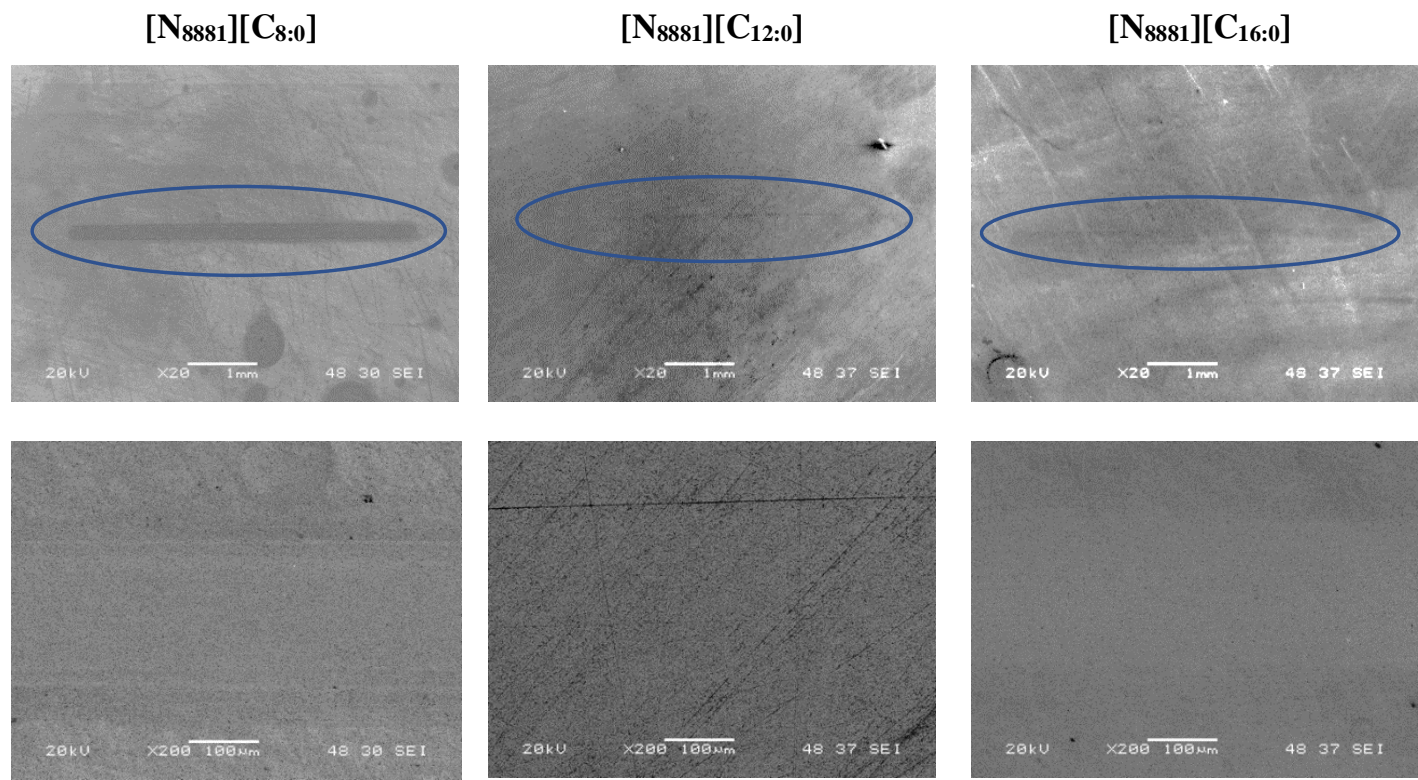

Fig. 7 Wear scar on the tungsten carbide discs after tribological tests with ionic liquid lubrication. 
$\left[\mathbf{N}_{8881}\right]\left[\mathbf{C}_{8: 0}\right]$
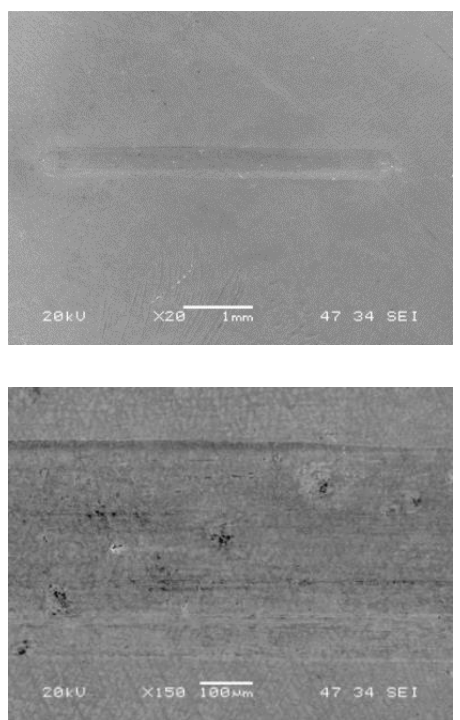

$\left[\mathrm{N}_{8881}\right]\left[\mathrm{C}_{12: 0}\right]$
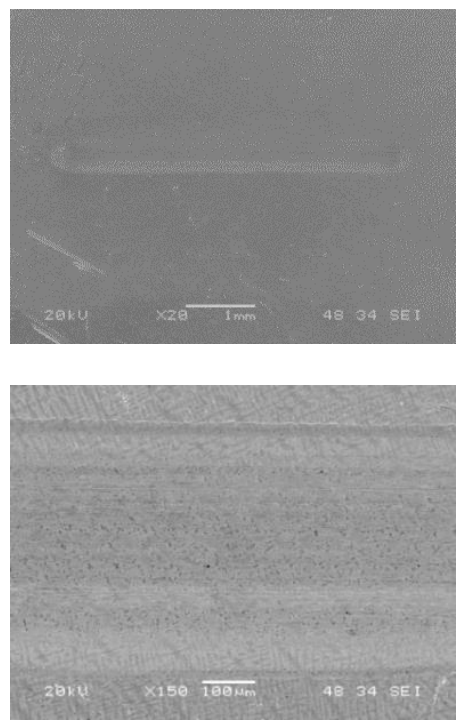

$\left[\mathbf{N}_{8881}\right]\left[\mathbf{C}_{16: 0}\right]$
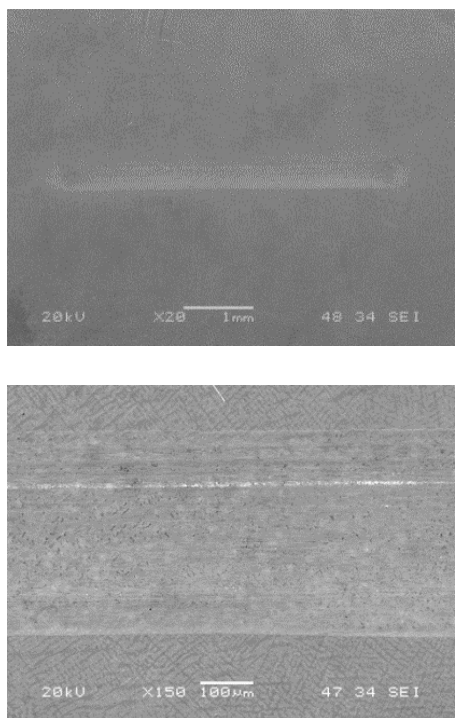

Fig. 8 Wear scar on the bronze discs after tribological tests with ionic liquid lubrication.

After all the tribological tests with the steel-aluminum pair, lubricated with each ionic liquid, steel debris from the ball (upper specimen) were found on the disc surface in the wear scar, Fig. 9. This contributed to the highest wear values reported in Fig. 4. The EDS analysis in the wear scar of the other discs (steel, bronze and copper) only found the chemical elements present in each material.

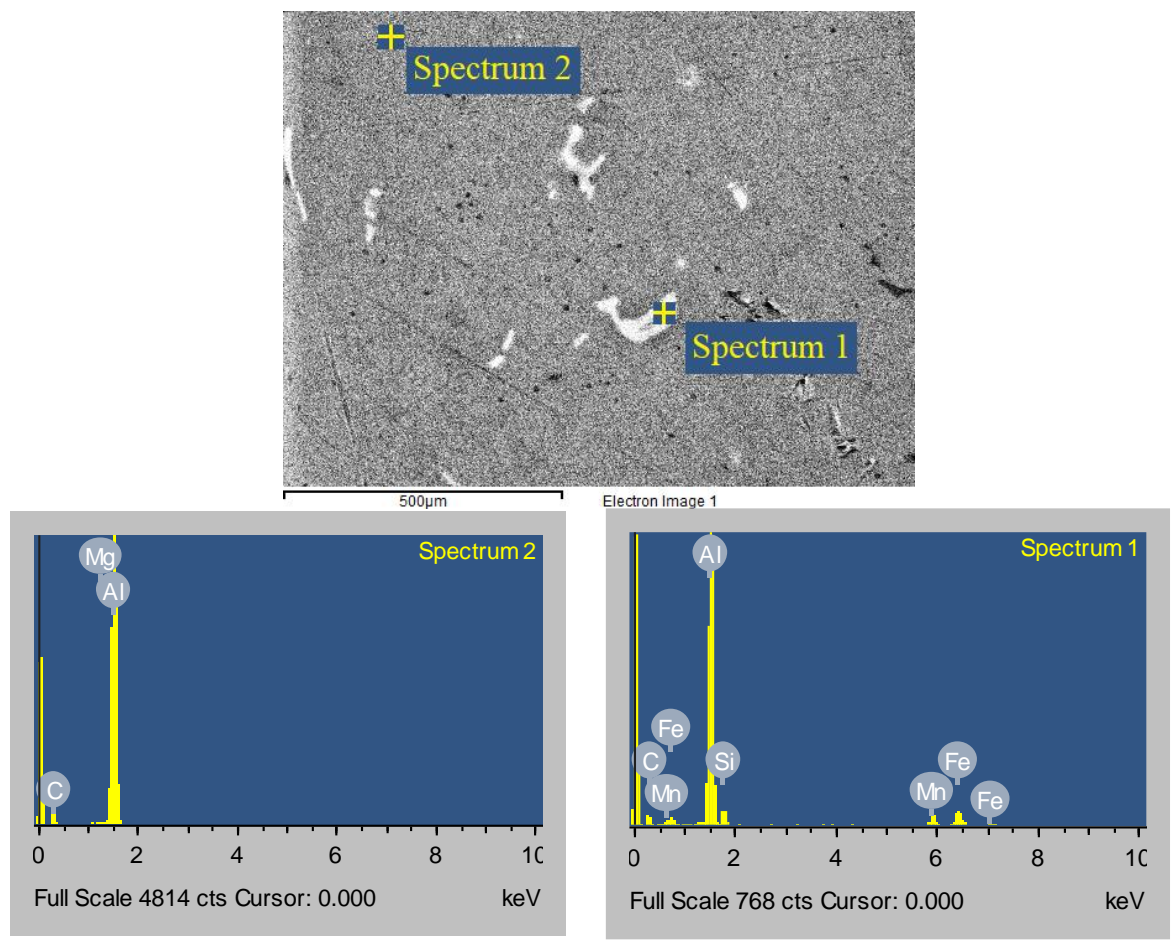

Fig. 9 Steel debris (spectrum 1) found in the wear scar (spectrum 2) after the test made with the steelaluminum pair and the $\left[\mathrm{N}_{8881}\right]\left[\mathrm{C}_{8: 0}\right]$ ionic liquid. 
The performance of each lubricant sample was compared to the others by analyzing the surfaces using the XPS spectroscopy technique. Aluminum samples did not show significant surface differences in the XPS analysis. Peak positions were $118.5 \mathrm{eV}$ for $\left[\mathrm{N}_{8881}\right]\left[\mathrm{C}_{8: 0}\right]$ and $\left[\mathrm{N}_{8881}\right]\left[\mathrm{C}_{12: 0}\right]$, and $117.5 \mathrm{eV}$ for $\left[\mathrm{N}_{8881}\right]\left[\mathrm{C}_{16: 0}\right]$. Both binding energies can be identified with $\mathrm{Al}_{2} \mathrm{O}_{3}$ according to the NIST database [55], which is to be expected, given the ability of aluminum surfaces to passivate by forming an aluminum oxide surface layer. Furthermore, the homogeneity in the values for the coefficient of friction is also consistent with our observation. Additionally, the work by Canyook et al. describes an increase in the coefficient of friction with oxidizing treatments [56]. Since the ionic liquids have similar structures, big differences in the oxidation capacities should not be expected and, therefore, they should show similar coefficients of friction, which is what was seen in the experiment.

Tungsten carbide samples showed almost no evidence of damage in any sample, regardless of the ionic liquid used. The similarity in the surface is in agreement with with the similar results obtained in both coefficient of friction and wear for these samples.

Bronze samples showed differing behavior depending on the ionic liquid used as lubricant. In the case of methyltrioctylamine octanoate $\left(\left[\mathrm{N}_{8881}\right]\left[\mathrm{C}_{8: 0}\right]\right)$, we identified three peaks for $\mathrm{Cu} 2 \mathrm{p}^{3 / 2}$ and two for tin $3 \mathrm{~d}^{5 / 2}$. Copper appeared at 931.1, 933.6 and $940.2 \mathrm{eV}$ (Fig. 10), assignable to metallic copper or $\mathrm{Cu}(0)$, copper (II) and a satellite peak, respectively [57], whereas tin appeared at 486.1 and $484.5 \mathrm{eV}$ (Fig. 11). The first peak for tin seems to be tin oxide, while lower binding energies normally refer to lower oxidation states, in this case $\mathrm{Sn}(0)$ [58]. The $\mathrm{Cu}(\mathrm{II}) / \mathrm{Cu}(0)$ ratio was 0.3 and the $\mathrm{Sn}(\mathrm{II}) / \mathrm{Sn}(0)$ was 7.5 (Table 3), indicating a much higher degree of oxidation in tin than in copper, which is to be expected, given the easier oxidation of tin compared to copper. When using methyltrioctylammonium dodecanate $\left(\left[\mathrm{N}_{8881}\right]\left[\mathrm{C}_{12: 0}\right]\right), \mathrm{Cu} 2 \mathrm{p}^{3 / 2}$ peaks were found at $930.3 \mathrm{eV}(\mathrm{Cu}(0)), 933.2 \mathrm{eV}(\mathrm{Cu}(\mathrm{II}))$ and $940.6 \mathrm{eV}$ (satellite), as can be seen in Fig. 10. The $\mathrm{Cu}(\mathrm{II}) / \mathrm{Cu}(0)$ ratio was 0.2 (Table 3), almost the same as in the previous case. Tin, on the other hand, showed a single peak at $485.4 \mathrm{eV}$ (Fig. 11), which probably means that only $\mathrm{Sn}(\mathrm{II})$ was present. A very similar situation is found when the lubrication takes place with methyltrioctylammonium hexadecanoate ([ $\left.\left.\mathrm{N}_{8881}\right]\left[\mathrm{C}_{16: 0}\right]\right)$. Copper peaks appear at $930.0 \mathrm{eV}(\mathrm{Cu}(0)), 932.8 \mathrm{eV}(\mathrm{Cu}(\mathrm{II}))$ and $939.5 \mathrm{eV}$ (satellite), as seen in Fig. 10, and tin (Fig. 11) shows a single peak at $485.0 \mathrm{eV}$, corresponding to $\mathrm{Sn}$ (II). In this case, the $\mathrm{Cu}(\mathrm{II}) / \mathrm{Cu}(0)$ ratio is 0.3 (Table 3 ).

According to these results, oxidation of the surface takes place mainly on tin rather than on copper, and it is more likely to happen in lubricants with longer carbon chains. Although the bronze samples do not show 
a significant difference in the COF for the three lubricants either, there is a clear increase in surface oxidation with the length of the carbon chain. This apparent discrepancy can be explained by considering the contribution of the different components of the surface. The oxidation in bronze takes place mainly in the tin, while copper keeps the same chemical status independently of the ionic liquid. It is likely that the copper has a stronger influence on the COF than tin and, therefore, the COF is not greatly affected by the higher degree of oxidation of tin.

Steel samples tested with $\left[\mathrm{N}_{8881}\right]\left[\mathrm{C}_{8: 0}\right]$ showed two different peaks for Fe2p ${ }^{3 / 2}$ (Fig. 12) at 709.0 and 705.8 eV, corresponding to $\mathrm{Fe}(\mathrm{III})$ and $\mathrm{Fe}(0)$, respectively, according to Mangolini and Mayer [59, 60] with an $\mathrm{Fe}(\mathrm{III}) / \mathrm{Fe}(0)$ ratio of 1.7 (Table 3 ). With the steel samples lubricated with $\left[\mathrm{N}_{8881}\right]\left[\mathrm{C}_{12: 0}\right]$, fitting was worse, but demonstrated the presence of $\mathrm{Fe}(\mathrm{III})$ at $710.6 \mathrm{eV}$ and $\mathrm{Fe}(0)$ at $707 \mathrm{eV}$ with a $\mathrm{Fe}(\mathrm{III}) / \mathrm{Fe}(0)$ ratio of 2.0 (Table 3). In the samples tested with $\left[\mathrm{N}_{8881}\right]\left[\mathrm{C}_{16: 0}\right], \mathrm{Fe} 2 \mathrm{p} 3 / 2$ peaks appeared at $706.1 \mathrm{eV}(\mathrm{Fe}(0))$ and 709.7 $\mathrm{eV}(\mathrm{Fe}(\mathrm{III}))$, with an area ratio $\mathrm{Fe}(\mathrm{III}) / \mathrm{Fe}(0)$ of 2.3 (Table 3$)$. According to the Fe oxidation mechanisms of Birks and the work by Tian [61], the formation of $\mathrm{Fe}_{3} \mathrm{O}_{4}$ provides excellent friction protection. This seems to agree with our results, where the coefficient of friction diminishes with a higher degree of oxidation. 


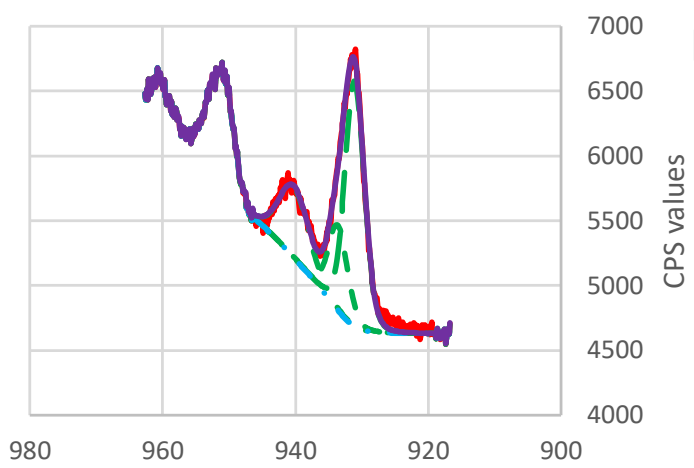

$\left[\mathrm{N}_{8881}\right]\left[\mathrm{C}_{8: 0}\right]$

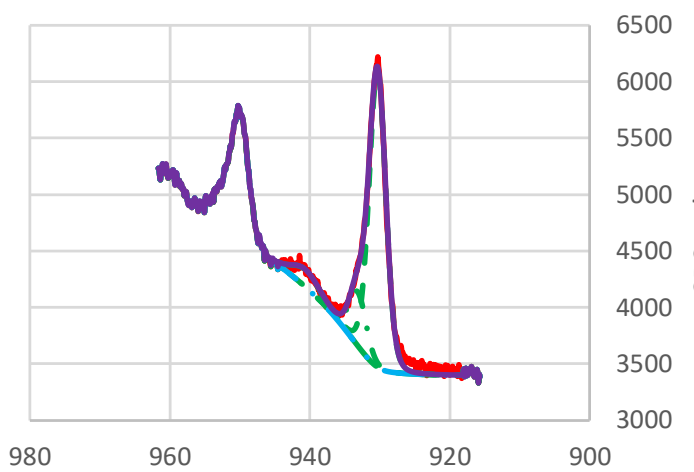

\section{$\left[\mathrm{N}_{8881}\right]\left[\mathrm{C}_{12}: \mathrm{o}\right]$}

$5000 \frac{\frac{y}{3}}{\frac{\pi}{2}}$

4500 芩

4000

500

3000

980

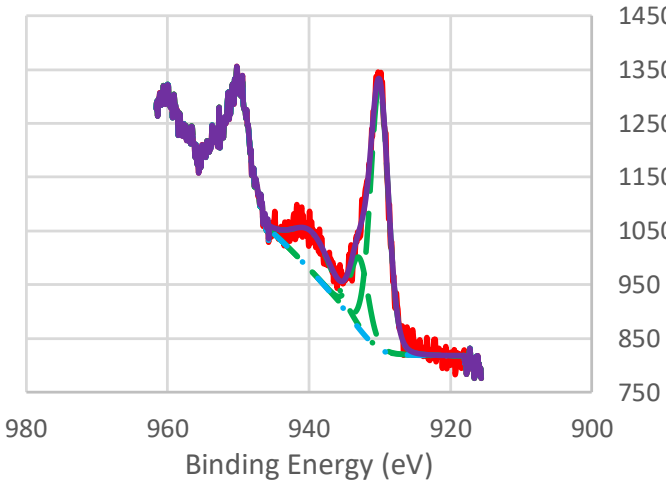

$\left[\mathrm{N}_{8881}\right]\left[\mathrm{C}_{\mathbf{1 6 : 0}}\right]$

-CPS_Cu $2 p$

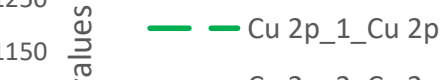

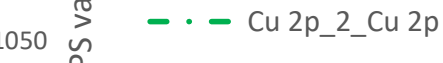

U U - - Cu 2p_3_Cu 2p

- - Background_Cu 2p

Envelope_Cu 2p

Fig. $10 \mathrm{Cu} 2 p$ XPS high-resolution spectra. 

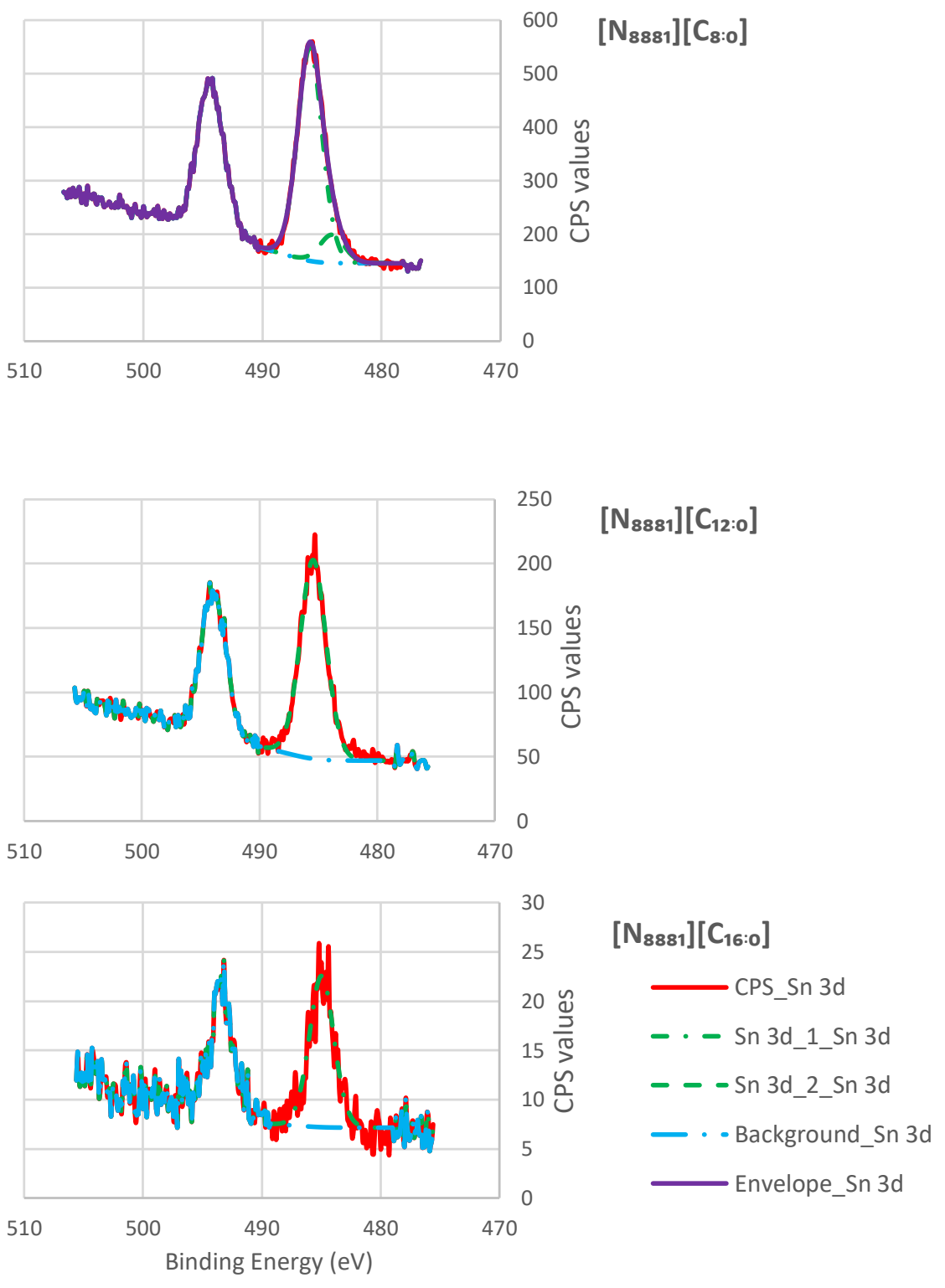

Fig. 11 Sn 3d XPS high-resolution spectra. 

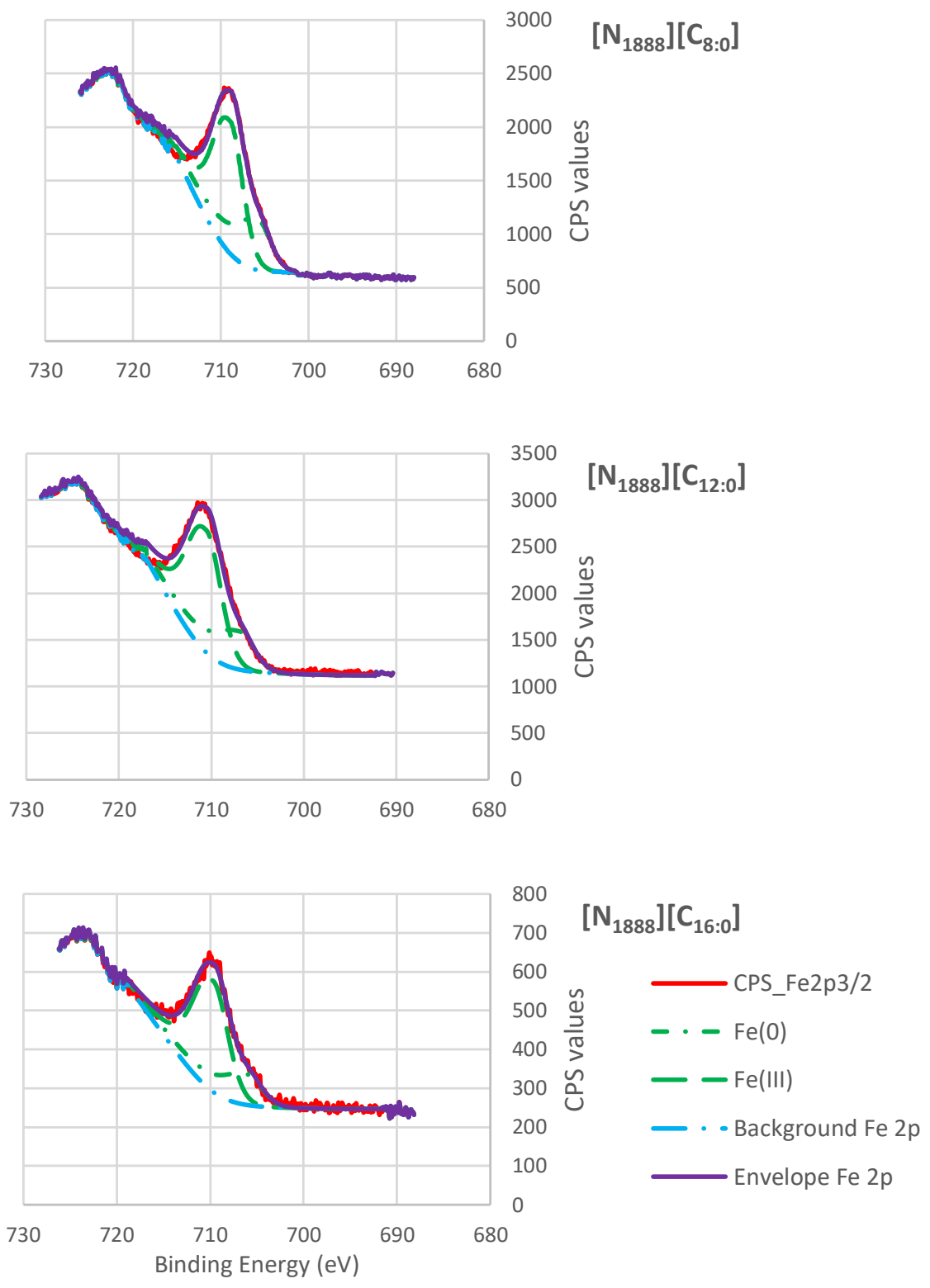

Fig. 12 Fe2p3/2XPS high-resolution spectra.

Table 3 Results for $\mathrm{Fe} 2 \mathrm{p}^{3 / 2}, \mathrm{Cu} 2 \mathrm{p}^{3 / 2}$ and $\mathrm{Sn} 3 \mathrm{~d}^{5 / 2}$ XPS bands.

\begin{tabular}{lllll}
\hline \multicolumn{1}{c}{ Materials } & \multicolumn{1}{c}{ Band } & {$\left[\mathrm{N}_{8881}\right]\left[\mathrm{C}_{8: 0}\right]$} & {$\left[\mathrm{N}_{8881}\right]\left[\mathrm{C}_{12: 0}\right]$} & {$\left[\mathrm{N}_{8881}\right]\left[\mathrm{C}_{16: 0}\right]$} \\
\hline Steel & $\mathrm{Fe}(\mathrm{III}) / \mathrm{Fe}(0)$ & 1.7 & 2.0 & 2.3 \\
\hline \multirow{2}{*}{ Bronze } & $\mathrm{Cu}(\mathrm{II}) / \mathrm{Cu}(0)$ & 0.3 & 0.2 & 0.3 \\
& $\mathrm{Sn}(\mathrm{II}) / \mathrm{Sn}(0)$ & 7.5 & $\infty$ & $\infty$ \\
\hline
\end{tabular}




\section{Conclusions}

Tribological behavior of three Fatty Acid Ionic Liquids (FAILs) with the same cation (methyltrioctylammonium) and different anions have been studied in four tribological contacts: steel-steel, steel-aluminum, steel-bronze and steel-tungsten carbide. The main conclusions obtained from the results of the experimental work are the following:

- The alkyl chain length of the anion affects the chemical composition of the wear surface during the tribological test. The oxidation of wear surfaces was greater with the use of ionic liquids with a longer alkyl chain in bronze and steel surfaces. In aluminum samples, the oxidation was similar for the different FAILs, while in tungsten carbide, no evidence of tribofilm formation was detected.

- In aluminum samples, wear was greater than in the case of the other three materials due to its lower hardness. The use of the IL with the longest alkyl chain in the anion resulted in a slight reduction in $\mathrm{COF}$ and wear.

- In tungsten carbide surfaces, wear was very small, due to their greater hardness in comparison with that of the counterpart (steel ball). In this case, the COF was higher than that of the other three material pairs as a result of greater contact pressure. The longest alkyl chain length in the anion resulted in a slight reduction in COF.

- In bronze surfaces, a slight increase in COF was measured in the test lubricated with the longest alkyl chain in the anion. Wear was not increased in this test, probably due to the higher oxidation of tin.

- In steel surfaces, the $\mathrm{Fe}_{3} \mathrm{O}_{4}$ formation promotes the antifriction behavior.

\section{Acknowledgements}

The authors would like to thank to the Ministry of Economy and Competitiveness (Spain) and FICYT (Foundation for the Promotion in Asturias of the Applied Scientific Research and Technology) for supporting the research projects MINECO-17-DPI2016-79690-R, MAT2015-66747-R and FC-GRUPINIDI/2018/000131. 


\section{References}

[1] Spikes H. The History and Mechanisms of ZDDP. Tribology Letters 2004;17(3);469-489. https://doi.org/10.1023/B:TRIL.0000044495.26882.b5

[2] Rokosz MJ, Chen AE, Lowe-Ma CK, Kucherov AV, Benson D, Paputa Peck MC, McCabe RW. Characterization of phosphorus-poisoned automotive exhaust catalysts. Applied Catalysis B Environmental 2001;33(3);205-215. https://doi.org/10.1016/S0926-3373(01)00165-5

[3] Minami I. Ionic Liquids in Tribology. Molecules 2009;14(6);2286-2305. https://doi.org/10.3390/molecules 14062286

[4] Bermúdez MD, Jiménez AE, Sanes J, Carrión FJ. Ionic liquids as advanced lubricant fluids. Molecules 2009;14(8);2888-2908. https://doi.org/10.3390/molecules14082888

[5] Somers A, Howlett P, MacFarlane D, Forsyth M. A review of ionic liquid lubricants. Lubricants 2013;1;3-21. https://doi.org/10.3390/lubricants1010003

[6] Palacio M, Bhushan B. A review of ionic liquids for green molecular lubrication in nanotechnology. Tribol. Lett. 2010;40;247-268. https://doi.org/10.1007/s11249-010-9671-8

[7] Van Rensselar J. Unleashing the potential of ionic liquids. Tribol. Lubr. Technol. 2010;66(4);24-31

[8] Zhou F, Liang Y, Liu W. Ionic liquid lubricants: designed chemistry for engineering applications. Chem. Soc. Rev. 2009;38;2590-2599. http://dx.doi.org/10.1039/B817899M

[9] Liu W, Ye C, Gong Q, Wang H, Wang P. Tribological performance of room-temperature ionic liquids as lubricant. Tribol. Lett. 2002;13;81-85. https://doi.org/10.1023/A:1020148514877

[10] Lu Q, Wang H, Ye C, Liu W, Xue Q. Room temperature ionic liquid 1-ethyl-3hexylimidazoliumbis(trifluoromethylsulfonyl)-imide as lubricant for steel/steel contact. Tribol. Int. 2004;37;547-552. https://doi.org/10.1016/j.triboint.2003.12.003

[11] Sanes J, Carrion FJ, Bermudez MD, Martinez-Nicolas G. Ionic liquids as lubricants of polystyrene and polyamide 6-steel contacts. Preparation and properties of new polymer-ionic liquid dispersions. Tribol. Lett. 21, 121-133 (2006). https://doi.org/10.1007/s11249-006-9028-5

[12] Hernández Battez A, Bartolomé M, Blanco D, Viesca JL, Fernández-González A, González R. Phosphonium cation-based ionic liquids as neat lubricants: Physicochemical and tribological performance. Tribol Int 2016;95;118-131. https://doi.org/10.1016/j.triboint.2015.11.015

[13] Mordukhovich G, Qu J, Howe JY, Bair S, Yu B, Luo H, Smolen- ski DJ, Blau PJ, Bunting BG, Dai S. A Low-Viscosity Ionic Liquid Demonstrating Superior Lubricating Performance from Mixed to Boundary Lubrication. Wear 2013;301(1);740-746. https://doi.org/10.1016/j.wear.2012.11.076

[14] Otero I, López ER, Reichelt M, Fernández J. Friction and Anti-Wear Properties of Two Tris (pentafluoroethyl) Tri- fluorophosphate Ionic Liquids as Neat Lubricants. Tribology International 2014;70;104-111. https://doi.org/10.1016/j.triboint.2013.10.002 
[15] Hernández Battez A, Blanco D, Fernández-González A, Mallada MT, González R, Viesca JL. Friction, wear and tribofilm formation with a $\left[\mathrm{NTf}_{2}\right]$ anion-based ionic liquid as neat lubricant. Tribol Int 2016;103:73-86. https://doi.org/10.1016/j.triboint.2016.06.038

[16] Itoga M, Aoki S, Suzuki A, Yoshida Y, Fujinami Y, Masuko M. Toward resolving anxiety about the accelerated corrosive wear of steel lubricated with the fluorine-containing ionic liquids at elevated temperature. Tribol Int 2016;93:640-50. https://doi.org/10.1016/j.triboint.2015.01.008

[17] Somers AE, Biddulph SM, Howlett PC, Sun J, MacFarlane DR, Forsyth M. A comparison of phosphorus and fluorine containing IL lubricants for steel on aluminium. Phys Chem Chem Phys 2012;14:8224. https://doi.org/10.1039/c2cp40736a

[18] Qu J, Blau PJ, Dai S, Luo H, Meyer III HM, Truhan JJ. Tribological characteristics of aluminum alloys sliding against steel lubricated by ammonium and imidazolium ionic liquids. Wear 2009;267(58);1226-1231. https://doi.org/10.1016/j.wear.2008.12.038

[19] Zhang H, Xia Y, Yao M, Jia Z, Liu Z. The influences of methyl group at C2 position in imidazolium ring on tribological properties. Tribol. Lett. 2009;36;105-111. https://doi.org/10.1007/s11249-009$\underline{9465-\mathrm{Z}}$

[20] Jimenez AE, Bermudez MD, Carrion FJ, Martinez-Nicolas G. Room temperature ionic liquids as lubricant additives in steel- aluminium contacts: influence of sliding velocity, normal load and temperature. Wear 2006;261;347-359. https://doi.org/10.1016/j.wear.2005.11.004

[21] Mo Y, Zhao W, Zhu M, Bai M. Nano/microtribological properties of ultrathin functionalized imidazolium wear-resistant ionic liquid films on single crystal silicon. Tribol. Lett. 2008;32;143-151. https://doi.org/10.1007/s11249-008-9371-9

[22] Iglesias P, Bermudez MD, Carrion FJ, Martinez-Nicolas G. Friction and wear of aluminium-steel contacts lubricated with ordered fluids-neutral and ionic liquid crystals as oil additives. Wear 2004;256;386-392. https://doi.org/10.1016/S0043-1648(03)00442-3

[23] Han Y, Qiao D, Zhang L, Feng D. Study of tribological performance and mechanism of phosphonate ionic liquids for steel / aluminum contact. Tribol Int 2015;84:71-80. https://doi.org/10.1016/j.triboint.2014.11.013

[24] Zeng Z, Chen Y, Wang D, Zhang J. Tribological Behaviors of Amorphous Cr Coatings Electrodeposited from Cr (III) Baths under Ionic Liquid Lubrication. Electrochemical and Solid- State Letters 2007;10(8);D85-D87. https://doi.org/10.1149/1.2746129

[25] Espinosa T, Sanes J, Jimenez AE, Bermudez MD. Protic Ammonium Carboxylate Ionic Liquid Lubricants of OFHC Copper. Wear 2013;303(1);495-509. https://doi.org/10.1016/j.wear.2013.03.041

[26] Xia Y, Sasaki S, Murakami T, Nakano M, Shi L, Wang H. Ionic liquid lubrication of electrodeposited nickel-Si3N4 composite coatings. Wear 2007;262;765-771. https://doi.org/10.1016/j.wear.2006.06.015 
[27] Kondo Y, Koyama T, Tsuboi R, Nakano M, Miyake K, Sasaki S. Tribological performance of halogen-free ionic liquids as lubricants of hard coatings and ceramics. Tribol Lett 2013;51:243-9. https://doi.org/10.1007/s11249-013-0159-1

[28] Jiménez A E, Bermudez MD. Ionic Liquids as Lubricants of Titanium-Steel Contact. Tribology Letters 2009;33(2);111-126. https://doi.org/10.1007/s11249-008-9396-0

[29] Viesca JL, Anand M, Blanco D, Fernández-González A, García A, Hadfield M. Tribological Behaviour of PVD Coatings Lubricated with a FAP- Anion-Based Ionic Liquid Used as an Additive. Lubricants 2016;4:8. https://doi.org/10.3390/lubricants4010008

[30] Liu W, Ye C, Chen Y, Ou Z, Sun DC. Tribological behavior of sialon ceramics sliding against steel lubricated by fluorine-containing oils. Tribol Int 2002;35:503-9. https://doi.org/10.1016/S0301$\underline{679 X(02) 00044-0}$

[31] Viesca JL, Mallada MT, Blanco,D, Fernández-González A, Espina-Casado J, González R, Hernández Battez A. Lubrication performance of an ammonium cation-based ionic liquid used as an additive in a polar oil, Tribology International 2017;116;422-430. https://doi.org/10.1016/j.triboint.2017.08.004

[32] Qu J, Truhan JJ, Dai S, Luo H, Blau PJ. Ionic liquids with ammonium cations as lubricants or additives, Tribology Letters 2006;22 (3);207-214. https://doi.org/10.1007/s11249-006-9081-0

[33] Oulego P, Blanco D, Ramos D, Viesca JL, Díaz M, Hernández Battez A, Environmental properties of phosphonium, imidazolium and ammonium cation-based ionic liquids as potential lubricant additives, Journal of Molecular Liquids 2018;272;937-947. https://doi.org/10.1016/j.molliq.2018.10.106

[34] Bhattacharjee A, Luis A, Santos JH, Lopes-da-Silva JA, Freire MG, Carvalho PJ, et al. Thermophysical properties of sulfonium- and ammonium-based ionic liquids. Fluid Phase Equilib 2014;381:36-45. https://doi.org/10.1016/j.fluid.2014.08.005

[35] Pisarova L, Gabler C, Dörr N, Pittenauer E, Allmaier G. Thermo-oxidative stability and corrosion properties of ammonium based ionic liquids. Tribol Int 2012;46:73-83. https://doi.org/10.1016/j.triboint.2011.03.014

[36] Stolte S, Steudte S, Areitioaurtena O, Pagano F, Thöming J, Stepnowski P, Igartua A. Ionic liquids as lubricants or lubrication additives: An ecotoxicity and biodegradability assessment. Chemosphere 2012;89:1135-41. https://doi.org/10.1016/j.chemosphere.2012.05.102

[37] Pejakovic V, Kronberger M, Mahrova M, Vilas M, Tojo E, Kalin M. Pyrrolidinium sulfate and ammonium sulfate ionic liquids as lubricant additives for steel/steel contact lubrication. Proc Inst Mech Eng Part J J Eng Tribol 2012;226:923-32. https://doi.org/10.1177/1350650112448978

[38] Barnhill WC, Luo H, Meyer HM, Ma C, Chi M, Papke BL, et al. Tertiary and Quaternary AmmoniumPhosphate Ionic Liquids as Lubricant Additives. Tribol Lett 2016;63:1-11. https://doi.org/10.1007/s11249-016-0707-6 
[39] Alvarez V H, Mattedi S, Martin-Pastor M, Aznar M; Iglesias M. Synthesis and thermophysical properties of two new protic long-chain ionic liquids with the oleate anion. Fluid Phase Equilib. 2010;299;42- 50. https://doi.org/10.1016/j.fluid.2010.08.022

[40] Zhou Y, Dyck J, Graham TW, Luo H, Leonard DN, Qu J. Ionic Liquids Composed of Phosphonium Cations and Organophosphate, Carboxylate, and Sulfonate Anions as Lubricant Antiwear Additives. Langmuir 2014;30;13301- 13311. https://doi.org/10.1021/la5032366

[41] Adhvaryu A, Erhan SZ, Perez JM. Tribological studies of thermally and chemically modified vegetable oils for use as environmentally friendly lubricants. Wear 2004;257(3-4);359-367. https://doi.org/10.1016/j.wear.2004.01.005

[42] Delgado MA, Quinchia LA, Spikes HA, Gallegos C. Suitability of ethyl cellulose as multifunctional additive for blends of vegetable oil-based lubricants. Journal of Cleaner Production 2017;151;1-9. https://doi.org/10.1016/j.jclepro.2017.03.023

[43] Gusain R, Khatri OP. Fatty acid ionic liquids as environmentally friendly lubricants for low friction and wear. RSC Advances 2016;6(82);78296-78302. https://doi.org/10.1039/C5RA25001C

[44] Gusain R, Dhingra S, Khatri OP. Fatty-Acid-Constituted Halogen-Free Ionic Liquids as Renewable, Environmentally Friendly, and High-Performance Lubricant Additives. Industrial and Engineering Chemistry Research 2016;55(4);856-865. https://doi.org/10.1021/acs.iecr.5b03347

[45] D. Parmentier, S.J. Metz, M.C. Kroon, Tetraalkylammonium oleate and linoleate based ionic liquids: promising extractants for metal salts, Green Chem. 15(1) (2013) 205-209. https://doi.org/10.1039/C2GC36458A.

[46] M.D. Avilés, F.J. Carrión, J. Sanes, M.D. Bermúdez, Effects of protic ionic liquid crystal additives on the water-lubricated sliding wear and friction of sapphire against stainless steel, Wear 408-409 (2018) 56-64.

[47] R. Gusain, S. Dhingra, O.P. Khatri, Fatty-acid-constituted halogen-free ionic liquids as renewable, environmentally friendly, and high-performance lubricant additives, Ind. Eng. Chem. Res. 55(4) (2016) 856-865. https://doi.org/10.1021/acs.iecr.5b03347.

[48] R. Gusain O.P. Khatri, Fatty acid ionic liquids as environmentally friendly lubricants for low friction and wear, RSC Adv. 6(5) (2016) 3462-3469. https://doi.org/10.1039/C5RA25001C.

[49] A.H. Battez, N. Rivera, D. Blanco, P. Oulego, J.L. Viesca, R. González, Physicochemical, traction and tribofilm formation properties of three octanoate-, laurate- and palmitate-anion based ionic liquids, J. Mol. Liq. 284 (2019) 639-646. https://doi.org/10.1016/j.molliq.2019.04.050.

[50] M. Fan, L. Ma, C. Zhang, Z. Wang, J. Ruan, M. Han, Y. Ren, C. Zhang, D. Yang, F. Zhou, W. Liu, Biobased green lubricants: physicochemical, tribological and toxicological properties of fatty acid 
ionic liquids, Trib. Trans. 61(2) (2017) 195-206. https://doi.org/10.1080/10402004.2017.1290856.

[51] P.K. Khatri, M.S. Aathira, G.D. Thakre, S.L. Jain, Synthesis and tribological behavior of fatty acid constituted tetramethylguanidinium (TMG) ionic liquids for a steel/steel contact, Mater. Sc. Eng. C 91 (2018) 208-217. https://doi.org/10.1016/j.msec.2018.05.038.

[52] A.Khan, R. Gusain, M. Sahai, O. P. Khatri, Fatty acids-derived protic ionic liquids as lubricant additive to synthetic lube base oil for enhancement of tribological properties, , J. Mol. Liq. 293 (2019) 111444. DOI: 10.1016/j.molliq.2019.111444.

[53] Hernández Battez A, Rivera N, Blanco D, Oulego P, Viesca JL, González R. Physicochemical, traction and tribofilm formation properties of three octanoate-, laurate- and palmitate-anion based ionic liquids. J Mol Liquids 2019;284;639-646. https://doi.org/10.1016/j.molliq.2019.04.050

[54] Gusain R, Bakshi PS, Panda S, Sharma OP, Gardas R, Khatri OP. Physicochemical and tribophysical properties of trioctylalkylammonium bis(salicylato)borate (N888n-BScB) ionic liquids: effect of alkyl chain length, Phys. Chem. Chem. Phys. 2017;19;6433-6442. https://doi.org/10.1039/c6cp05990b

[55] NIST database https://srdata.nist.gov/xps/, last accessed april 4, 2019.

[56] Canyook R, Seubsom P, Sang-Ngean J, Trirujirapapong T, Taweesup K. Influences of sealing solutions on anodized layer properties of 7075 aluminium alloy. Materials Today: Proceedings 2018;5;9483-9488. https://doi.org/10.1016/j.matpr.2017.10.128

[57] Squarzialupi MC, Bernardini GP, Faso V, Atrei A, Rovida G. Characterisation by XPS of the corrosion patina formed on bronze surfaces. Journal of Cultural Heritage 2002;3;199-204. https://doi.org/10.1016/S1296-2074(02)01179-2

[58] Equey S, Houriet A, Mischler S. Wear and frictional mechanisms of copper-based bearing alloys. Wear 2011;273;9-16. https://doi.org/10.1016/j.wear.2011.03.030

[59] Mangolini F, Rossi A, Spencer ND. Influence of metallic and oxidized iron/steel on the reactivity of triphenyl phosphorothionate in oil solution. Tribol. Int. 44, 670-683 (2011). https://doi.org/10.1016/j.triboint.2010.02.009

[60] Mayer T. Black spots on carbon steel after contact to lubricating oil with extreme pressure additives: an XPS study. Appl. Surf. Sci. 2001;179;257-262. https://doi.org/10.1016/S0169-4332(01)00292-6

[61] Tian H, Wang C, Guo M, Tang Z, Wei S, Xu B. Influence of Ni and Cr on the high-temperature wear resistance of FeNiCrAl coatings. Results in Physics 2019;12;959-969. https://doi.org/10.1016/j.rinp.2018.12.061 